\title{
AUTOMOTIVE ALTERNATOR NOISE TYPES AND SOLUTIONS FOR NOISE REDUCTION BASED ON COMPONENT IMPROVEMENTS
}

\author{
Patrick Carvalho $^{1}$, Luciano Faria ${ }^{2}$, Lucas Oliveira ${ }^{3}$ e Samuel Celestino ${ }^{4}$ \\ ${ }^{1}$ Valeo Sistemas Automotivos \\ ${ }^{2}$ Valeo Sistemas Automotivos \\ ${ }^{3}$ Valeo Sistemas Automotivos \\ ${ }^{4}$ Valeo Sistemas Automotivos \\ E-mails: patrick.carvalho@valeo.com, luciano.faria@valeo.com, lucas.oliveira@valeo.com, \\ samuel.celestino@valeo.com.
}

\begin{abstract}
Noise reduction inside a vehicle cabin improve the comfort of vehicle passenger and also enhance the experience of drive a car, therefore the research for noise reduction under vehicles components are mandatory, this paper shows the main points under evaluation of vehicle noise, also shows the comparison between 4 different modifications on an alternator in order to show how is possible to evaluate the noise generated and also with demonstrate that reduce the air gap variation through stator inner perimeter and also increase of stiffness of claw pole helps to reduce average $4 \mathrm{~dB}$ on electromagnetic noise.
\end{abstract}

\section{INTRODUCTION}

The automotive industry is constantly investing in design development and solutions to reduce acoustic noise aiming the comfort and customer satisfaction. The components that are part of the vehicle powertrain are responsible for a portion of this noise.

The alternator is responsible for keeping the battery load charged and generating electrical energy for some car peripherals. Due to its operation it becomes a natural electromagnetic and aerodynamic noise generator. This article will contribute to understand the types of noise, its main causes and solutions for acoustic improvement.

The main objective of this article is to reduce the noise present in the alternator with the design already established by changing only process parameters and current components for this that 5 situations will be tested in a semi anechoic chamber and the results will be compared to determine which gain in $\mathrm{dB}$ is possible to achieve with each proposal.

\section{PRINCIPLE OF ALTERNATOR FUNCTIONALITY AND STRUCTURE}

Alternators are electrical machines utilized on vehicles which are responsible to convert the mechanical energy generated by engine into electrical energy, the converted energy is required to supply several vehicle's peripherals such vehicle control unit, lights, dashboard, radio and so on. 
Automotive alternators have a structure close to a synchronous generators which a field current is applied to rotor bobbin, the current establishes a sinusoidal flux through the air gap, when rotor moves the flux linkage will change thought the stator (or armature) windings, inducing voltage on stator windings, the principle of operation of synchronous machines are vastly studied on several references [1] [2].

There are major differences between alternator and standard synchronous generators, the differences are related to rotor poles format, output rectifying, and voltage level control. Alternator normally held a pole rotor in a trapezoidal format of a claw, while synchronous generators pole normally are composed by salient pole rotors or cylindrical rotors (non salient pole), claw pole principal application is to reduce flux linkage harmonics thus reduce electromagnetic noise, rotor's claw poles has significant influence on alternators noise therefore special attention is given to this component [3]. Alternators also have the output available on stator phases rectified by a diode bridge. Also alternator has output level control, which is performed by a regulator, the regulator dynamically change the field current injected on rotor bobbin in order to reach different level of output voltage.

There are several different configurations and design of alternators, however this paper will base the studies on a three phase 12 poles alternator with nominal current of $120 \mathrm{~A}$. The figure 1 we can see the alternator used in this paper with the identification of the components.

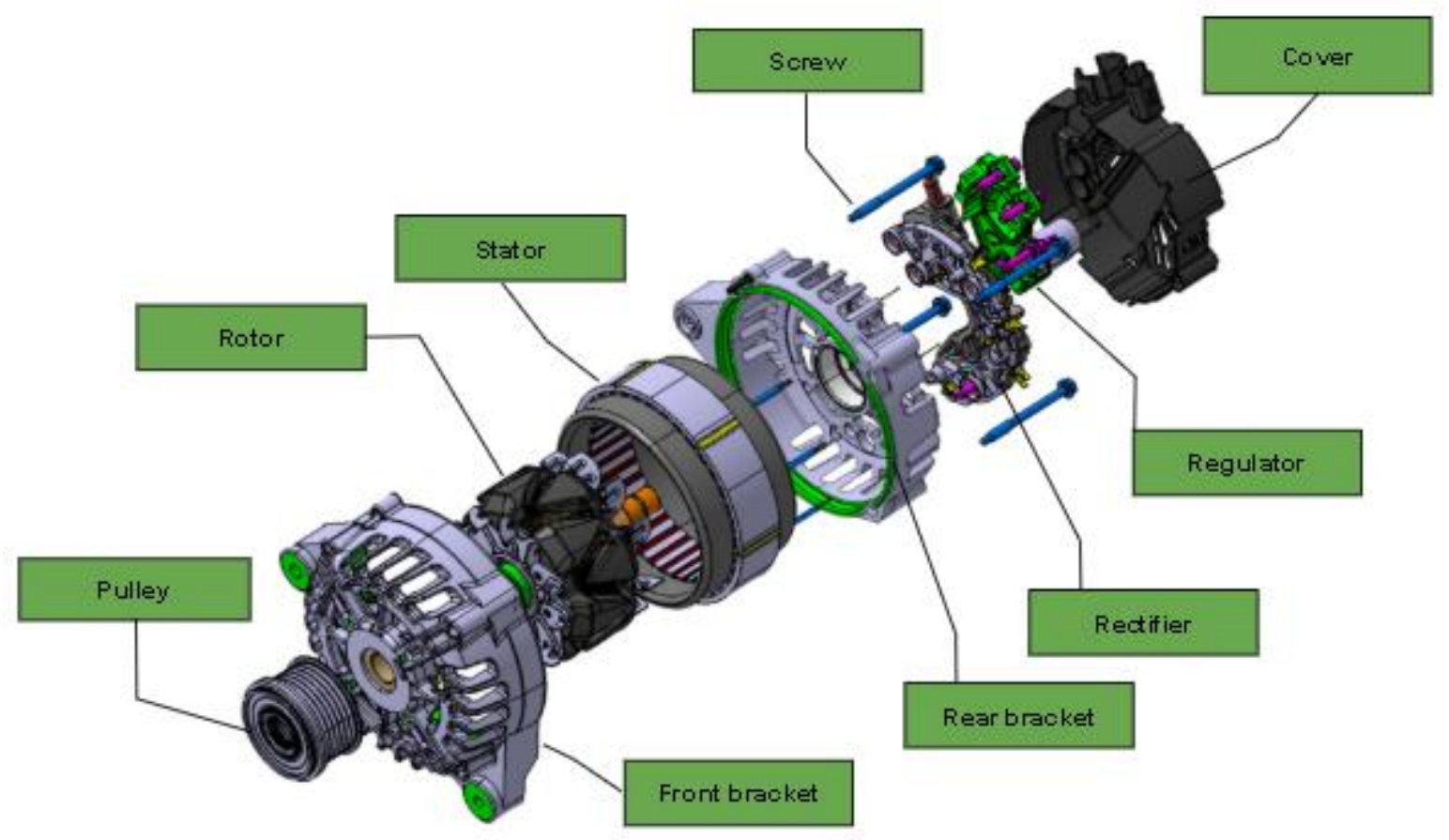

Fig. 1. Alternator with components

\section{NOISE EVALUATION AND ORDER ANALYSIS}

An important method to evaluate noise on rotating machine is to isolate the noise emitted by every component, the discrimination of noise are commonly named as discretization by orders. Every rotating component radiates a noise in a frequency directly related to its mechanical structure (number of poles, number of slots), all component noises contribute to the overall 
noise, when rotation speed increase the noise frequency radiated by the component increases as well. Therefore orders track the relationship between machine rotation speed and noise radiated by the component, the figure 2 illustrates the orders of 5 different components (green, grey, red, orange and yellow) plus overall noise (blue) evaluated for a range of rotation speed given in RPM.

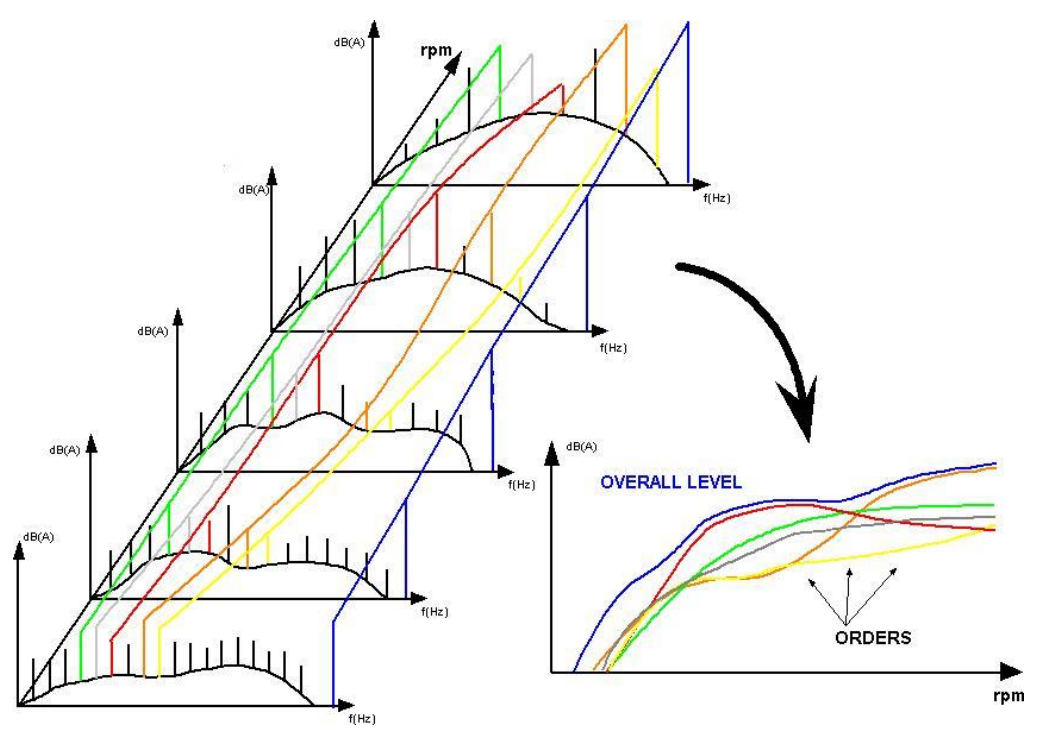

Fig. 2. Illustration of orders chart

For alternators the noise are commonly divided by two main sources, aerodynamic noises and electromagnetic noises. Figure 3 shows Ishikawa diagram with factors linked with aerodynamic noises.

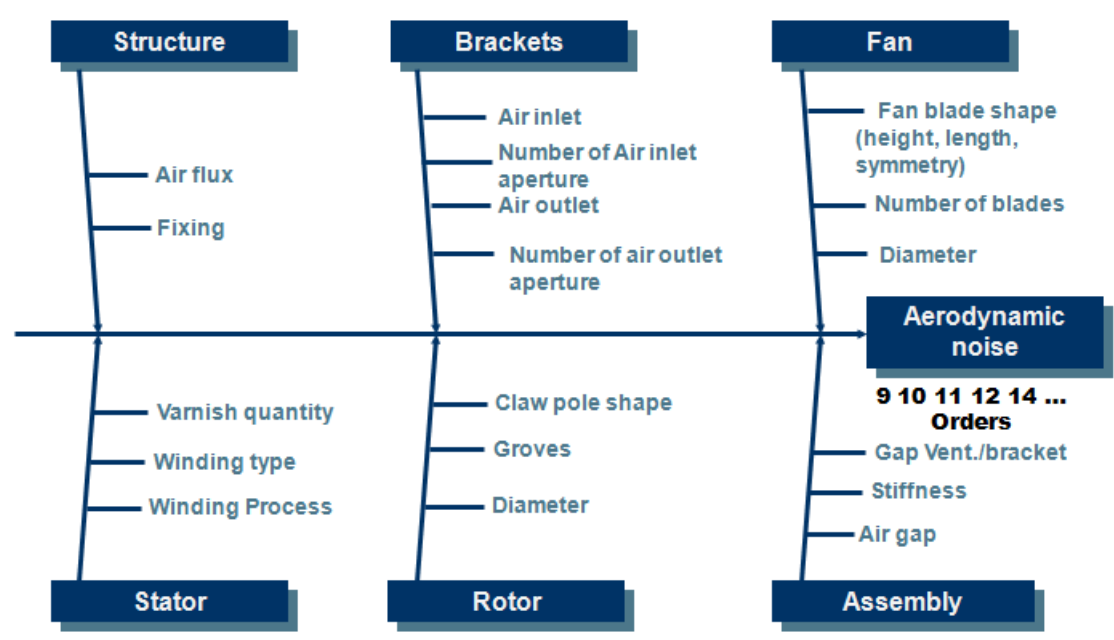

Fig. 3. Ishikawa diagram for aerodynamic noises

Orders for aerodynamic noise are commonly related to order 9, 10, 11, 12 and 14 due to fan blades quantity, number of apertures for air inlet/outlet. For magnet noise, orders 36, 48, 72 and 96 are commonly related, they are linked to pair of poles quantity and numbers of phases. Figure 4 shows Ishikawa diagram with factors related for electromagnetic noises. 


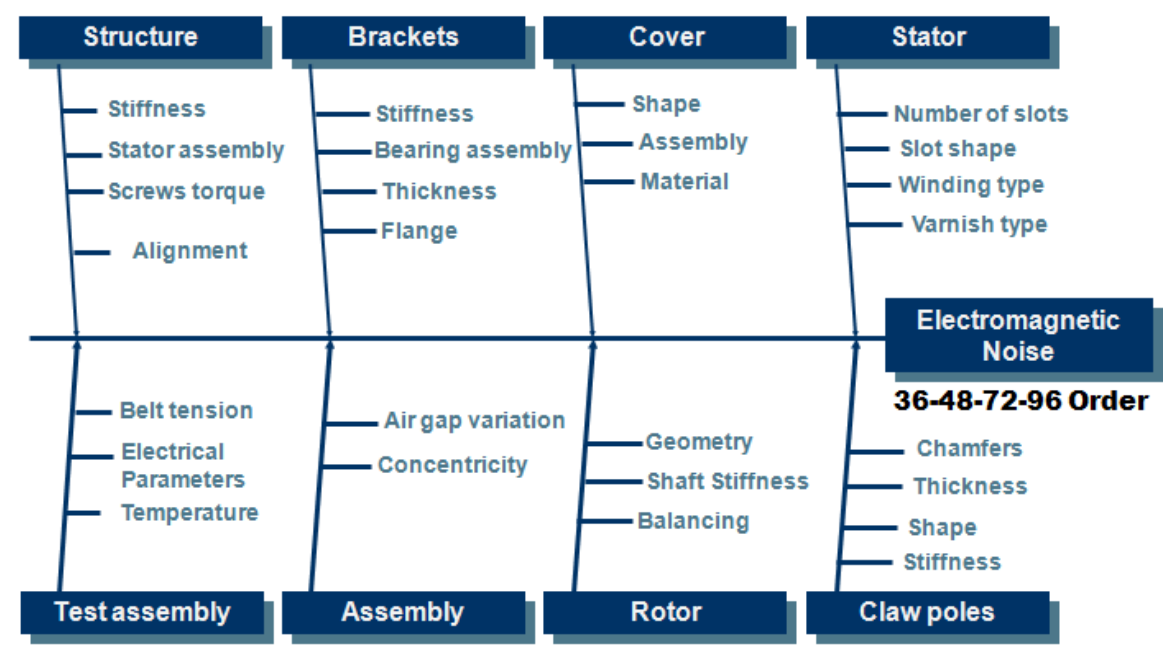

Fig. 4. Ishikawa diagram for electromagnetic noises

For example, order 36 is related to number of pole pairs and number of phases to reach the order number the equation (1) can be applied.

$$
\text { Principal Order }=N P P_{X} N P H \times 2
$$

Where NPP stands for number of pole pairs and NPH stands for number of phases.

Also alternators can present mechanical noise, they are normally linked to component issues or assembly issue. Figure 5 shows Ishikawa diagram with factors related for mechanical noises.

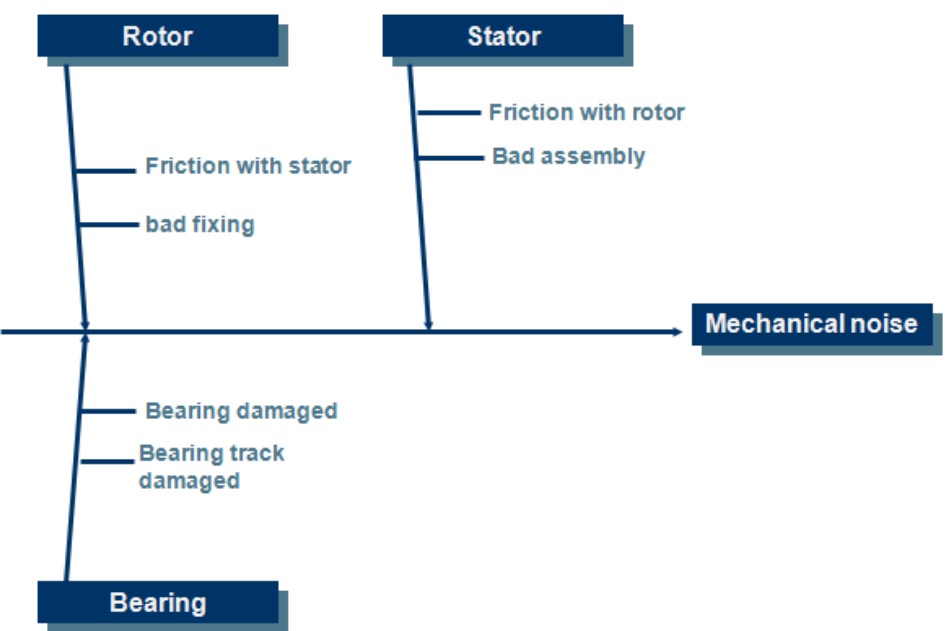

Fig. 5. Ishikawa diagram for mechanical noises

\section{TEST METHOD}

For this paper 5 different conditions of alternators were tested:

- Baseline (normal production alternator);

- Reduce concentricity of rear bearing index: limited to $0.015 \mathrm{~mm}$ max;

- Change on rotor varnish composition: increase of $11 \%$ of solid particles on composition of varnish; 
- Increase rotor varnish thickness layer: submit rotor two times to impregnation process to increase varnish thickness;

- Reduce claw pole misalignment: restrict claw pole (rear and front) misalignment in max $1^{\circ}$.

Those 5 different samples were tested in order to compare the influence under the electromagnet noise generated by the alternator (order $36 ; 3$ phases 12 poles) in this special case will be evaluated the range of 2000 RPM to 4000 RPM related to vehicle idle speed and also between 11000 RPM to 13000 RPM related to claw pole resonance noise which represents the highest peak of noise. All samples were submitted to same test condition, on semi anechoic chamber (Figure 6).

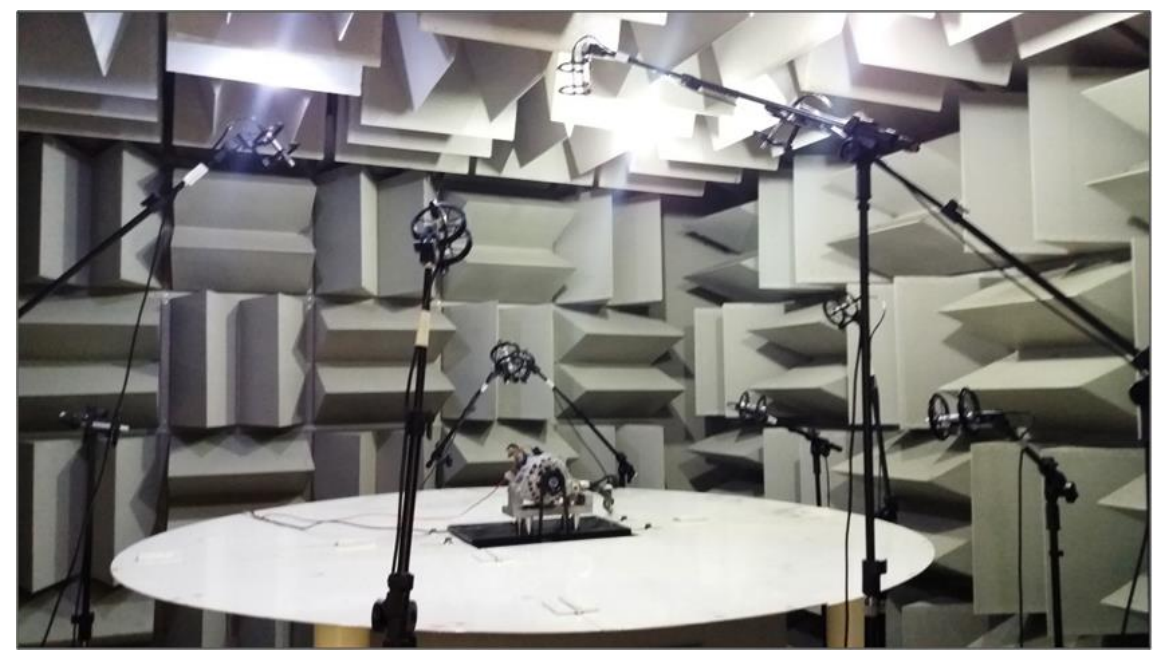

Fig. 6. Semi anechoic chamber utilized on tests

Acquisitions were made with a 10 microphones with frequency band of $3.15 \mathrm{~Hz}$ to $20 \mathrm{kHz}$, sensibility of $50 \mathrm{mV} / \mathrm{Pa}$, connected to acquisition system with sampling rate of $51.2 \mathrm{kHz}$.

\section{RESULTS}

Table 1 presents average sound pressure level values results observed in alternator's low rotation speed (2000 RPM to 4000 RPM) and also high rotation speed (11000 RPM to 13000 RPM), possible to verify that reducing the concentricity of rear bearing index reduce almost $5 \mathrm{~dB}$ in low rotation speed, also reduce almost $3 \mathrm{~dB}$ in high rotation speed. Also varnish thickness increase showed a reduction of $4 \mathrm{~dB}$ in low rotation and $5 \mathrm{~dB}$ in high rotation, Claw pole misalignment was effective only for low rotation speed and varnish composition showed no variation.

\begin{tabular}{|c|c|c|c|c|c|}
\hline $\begin{array}{r}\text { Alternator Rotation } \begin{array}{r}\text { Speed } \\
\text { (RPM) }\end{array}\end{array}$ & $\begin{array}{r}\text { Baseline } \\
\text { (dBA) }\end{array}$ & $\begin{array}{r}\text { Varnish } \\
\text { composition } \\
(\mathrm{dBA})\end{array}$ & $\begin{array}{r}\text { Claw pole } \\
\text { misalignment } \\
(\mathrm{dBA})\end{array}$ & $\begin{array}{r}\text { Concentricity } \\
\text { bearing index } \\
\text { (dBA) }\end{array}$ & $\begin{array}{r}\text { Varnish } \\
\text { thickness } \\
\text { (dBA) }\end{array}$ \\
\hline $2 \mathrm{kRPM}$ to $4 \mathrm{kRPM}$ & 64.90 & 65.63 & 60.53 & 59.98 & 60.33 \\
\hline $11 \mathrm{kRPM}$ to $13 \mathrm{kRPM}$ & 91.48 & 91.51 & 93.69 & 88.82 & 86.89 \\
\hline
\end{tabular}

Figure 7 shows the chart with acquisition results for the 5 different conditions. 


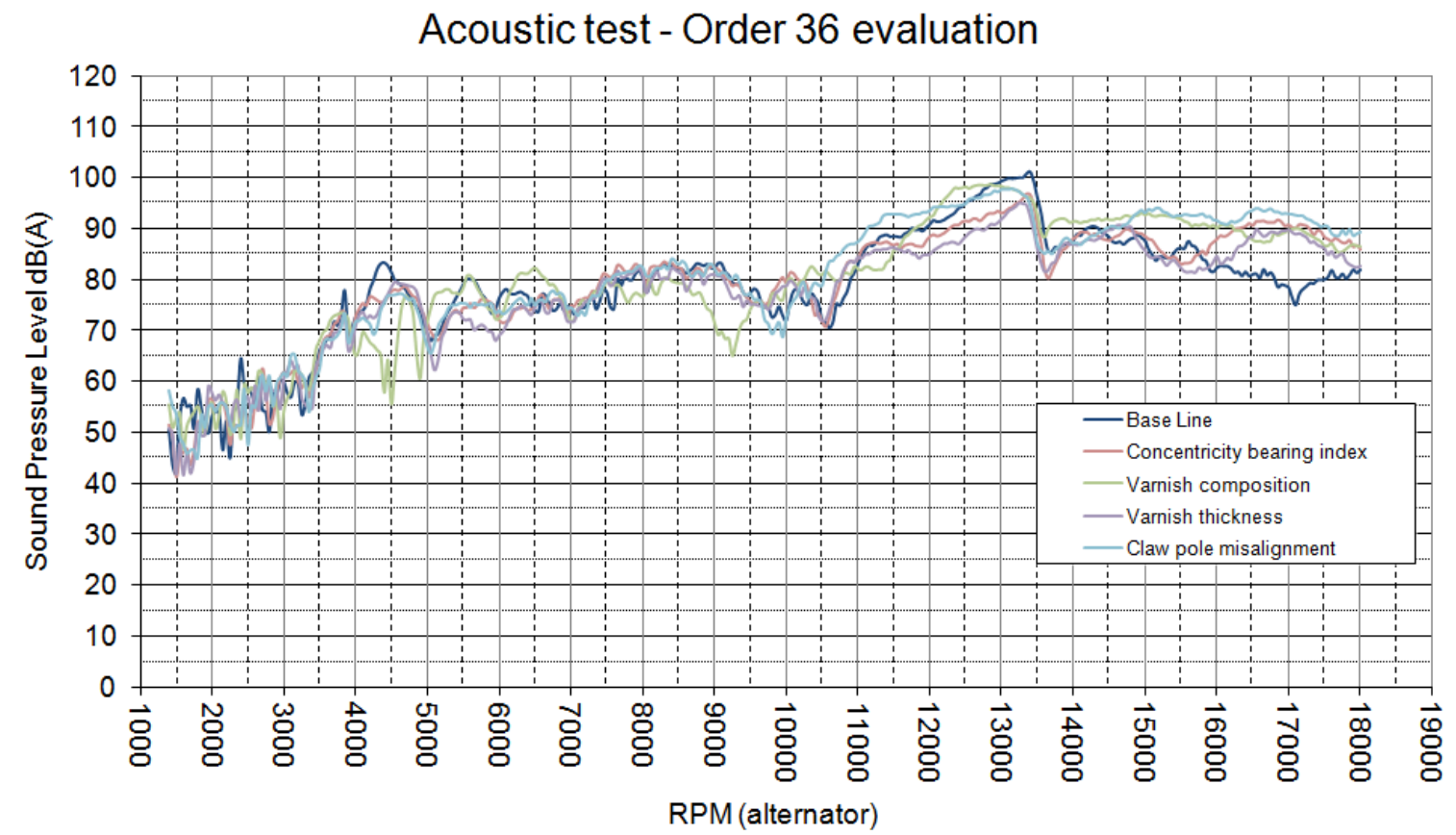

Fig. 7. Acoustic test result chart for order 36 analyses

\section{CONCLUSION}

This paper present the main points of acoustic evaluation of an automotive alternator, it presents 5 different configurations of samples in order to identify improvements on acoustic performance based on modifications of alternator components. As results was verified that reducing the concentricity of rear bearing index is a good way to reduce noise generated by alternator this effect is related to reduction of air gap variation, also is verified that increasing the thickness of varnish layer also reduces the noise generated by alternator at rate that increase of varnish also increase the claw stuffiness reducing resonances.

\section{REFERENCES}

[1] SEN, P. Principles of Electric machines and power electronics, 2th ed. John Wiley \& Sons, 1997 p. 292.

[2] FITZGERALD, A.E; KINGSKEY C. Electric Machinery, 6th ed. McGraw-Hill Companies, Inc., 2003 p. 239.

[3] EVERSMAN, W; BURNS, S; PEKAREK, S; Bai, H; TICHENOR, J. Noise generation mechanisms in claw pole alternators; Journal of Sound and Vibration 283 (2005) 369-400. 